\title{
José Saramago: hibridismo e transformação dos gêneros literários
}

\section{Vera Bastazin*}

Resumo: O presente trabalho tem como proposta o estudo do processo de hibridização e transformação dos gêneros literários na obra A bagagem do viajante, de José Saramago. A estratégia de análise é realizada pela diferenciação entre a crônica e o conto como modalidades do texto literário. Isto porque, na referida obra, a crônica tende a se afastar da referencialidade factual e a se aproximar, mais ou menos intensamente, da linguagem poética.

Palavras-chave: conto; crônica; gêneros literários; hibridização; José Saramago.

\begin{abstract}
This is a study of the processes of hybridism and transformation of literary genres applied to A bagagem do viajante by José Saramago. Considering that in Saramago's literary work the chronicle tends to move away from factual referentiality and to get closer, with more or less intensity, to poetic language, the strategies used in the analysis aim at drawing a distinction between the chronicle and the short story, viewed as different categories of literary text.
\end{abstract}

Keywords: short story; chronicle; literary genre; hybridism; Jose Saramago.

Gêneros literários e processos de hibridização constituem o ponto de partida teórico para o desenvolvimento deste trabalho. Refletir sobre as possíveis relações entre a crônica e o conto e a constituição da linguagem que se transforma da referencialidade para a caracterização poética é estratégia que motiva a leitura e análise das formas literárias em questão. A mudança de dominante que se observa na construção das crônicas da obra $A$ Bagagem do viajante, de José Saramago, é questão que abre espaço para se repensar os gêneros literários no contexto da modernidade. Indagar sobre os limites e as controvérsias que envolvem diferentes modalidades de textos literários é de fundamental importância para a reflexão e possíveis delimitações da crônica e do conto como formas literárias pertencentes ao rol dos gêneros trabalhados por José Saramago.

\footnotetext{
* Vera Bastazin é professora doutor de Teoria Literária e Literatura Brasileira e Portuguesa na Pós-Graduação de Literatura e Crítica Literária da PUC-SP; sua última publicação é o livro Mito e Poética na Literatura Contemporânea (São Paulo: Ateliê, 2006). Encontra-se, no prelo, Literatura Infantil e Juvenil: uma proposta interdisciplinar (São Paulo: Conexão Universidade/ Escola, 2007)
} 


\section{Gêneros literários: uma reflexão inicial e retrospectiva}

Refletir sobre os gêneros literários, tal como sobre a maioria das questões de literatura, assemelha-se à tentativa de mapear uma região em constante mutabilidade. $\mathrm{O}$ tratamento que se dedica à literatura ou às artes em geral, resulta em atribuir, por aqueles que sobre elas se debruçam, variados conceitos e funções, sempre atrelados às condições históricas e sociais de cada tempo e lugar.

Quer pela natureza, quer pelas características composicionais intrínsecas da obra literária, a apreensão e formulação de um conceito nunca foi, e provavelmente nunca será, tarefa pacífica, até mesmo pelo vínculo que a obra estabelece com seu criador - alguém genética, histórica e socialmente mutável e, em permanente estado de vir-a-ser.

Todavia, a elaboração dos conceitos sobre a arte em geral tem para nós, da civilização ocidental, um referente inicial inquestionável: a Grécia antiga e seus grandes pensadores. Retomar aos gregos, para quem a arte era uma habilidade específica que visava a determinados fins, é buscar aqueles que primeiro se dedicaram à reflexão, discussão e registro sobre as questões da arte em geral e da literatura em particular.

Discípulo de Platão e instigado por este, Aristóteles debruçou-se sobre a questão do fenômeno literário e deu encaminhamentos inovadores às proposições iniciais de Platão, o qual entendia a arte como ensinamento moral e instrumento pedagógico para a formação do cidadão ateniense, além de elaborar advertências para o perigo que significava o espaço das artes. Vista como perigosa e maléfica ao homem, a manifestação artística, segundo Platão, distorcia a realidade oferecendo ao cidadão informações falsas sobre os fatos, de maneira a não contribuir com o seu crescimento como homem apoiado no bem, na justiça e na verdade.

Contrariando as idéias de seu mestre, Aristóteles vai formular os primeiros conceitos ligados à arte, em especial à literatura, registrando o conceito de Mimeses como maneira de transformação do real. 'Trans-formar', segundo a proposta aristotélica, significa mudar a forma, imprimir nela uma nova maneira de ver e de interpretar o real. Diferentemente de Platão, que considerava a arte como cópia distorcida, e, portanto, falsa e desprezível do real, Aristóteles imprimia-lhe um valor altamente positivo - fosse pela originalidade expressiva trazida em seu bojo, fosse pela condição potencial de criar novos olhares, novas formas de percepção do objeto e, por extensão, do próprio mundo. Nessa controvérsia entre cópia perigosa e desprezível e mimeses criativa reside a primeira grande contribuição ligada à natureza e valor do objeto literário. Até hoje, as contribuições deixadas pelos filósofos gregos representam aspectos fundamentais para qualquer reflexão sobre o fenômeno literário. 
Atenhamo-nos um pouco à questão.

Desde a imitação que mais se aproxima, até aquela que mais se distancia do real, todas têm como referente um modelo, seja ele sensível ou inteligível. A imitação é um fenômeno comportamental intimamente ligado ao homem que, em princípio, tem todo seu processo de aprendizagem alicerçado em comportamentos imitativos. Todavia, imitar não é criar uma réplica perfeita do modelo - o que significaria a criação de um duplo. Ou seja, uma representação que assumisse o lugar do próprio objeto representado criaria, como conseqüência, o esvaziamento do modelo/ou signo representado. Neste sentido, é preciso ter claro que o ser mimético tal como seu modelo são de naturezas distintas. O signo original ou modelo é sempre mais perfeito ou mais completo que a imagem representada. O primeiro como modelo - contém informações que o segundo terá perdido (ou reduzido, ou ainda, fragmentado) em seu processo de apreensão e representação.

Assim, todo processo imitativo ou de representação traz consigo uma relação intrínseca de semelhança e/ou dessemelhança que se evidencia quando o imitado é confrontado ao modelo ou signo original. É nessa perspectiva que toda imagem reproduzida é presença e ausência de seu modelo. Ela traz consigo, concomitantemente, semelhanças e ausências (ou distorções) que a impedem de ser confundida com o modelo. Toda imitação revela a natureza que a envolve como objeto de representação. No universo dos fenômenos representados, a imagem (ou representação) será mais perfeita quanto mais semelhante for ao modelo, sem, contudo, confundir-se com ele. Lembramos, ainda, que toda representação almeja aproximar-se ao máximo do objeto imitado, todavia, apesar de seu esforço, ela será sempre incompleta (pois, se chegasse a ser completa, confundir-se-ia com o próprio objeto, deixando, portanto, de ser representação).

A importância da representação reside no fato dela poder presentificar o objeto mesmo em sua ausência. É nesse sentido, que Platão afirma que o sensível imita o inteligível ressalta-se que esta questão permanece como fundamental até os nossos dias, quando se discutem os valores e pressupostos da arte. Nessa perspectiva, talvez possamos contrapor Platão a Aristóteles, pois, para esse último, a representação de um objeto pode, por suas qualidades intrínsecas, conduzir à criação de um novo signo. Veja-se o caso da obra literária que não necessariamente remete a algo ou alguém já existente, mas, ao contrário, tem o poder de criar uma determinada realidade não anteriormente existente. $\mathrm{Na}$ arte, os processos de criação acabam por sugerir realidades virtuais, isto é, possíveis de existir - eis aqui presente o conceito aristotélico da Verossimilhança. 
Retomando o enfoque sobre mimeses, de uma forma mais global, verificamos que é em relação a esse conceito que se abre espaço para a reflexão e sistematização de um dos núcleos mais antigos dos estudos literários: a questão dos gêneros.

A princípio, compreendida apenas como duas vertentes - técnico e formal -, a teoria dos gêneros emerge como uma distinção entre poesia e prosa: "falarei em prosa, pois não sou poeta..." (Platão, 1964, p.72). No livro III de A República (394 a.C), o filósofo assinala uma distinção que constitui a base primária da questão, evidenciando uma diferença que se manifesta apenas pela forma. Esta distinção será rebatida por Aristóteles (s/d) que deixa claro, não ser a forma em verso de uso exclusivo do poeta. Em Aristóteles, no mais antigo estudo sobre os gêneros literários, encontra-se também a indicação ao livro III d'A República, quando este registra a primeira referência, no pensamento ocidental, aos gêneros literários, propondo as seguintes diferenciações:

\begin{tabular}{l|l} 
1. a tragédia e a comédia & $\begin{array}{l}\text { Ficções poéticas que se desenvolvem inteiramente } \\
\text { por imitação }\end{array}$ \\
\hline 2. o ditirambo & Estilo em que o poeta é o único a falar \\
\hline 3. a poesia épica & Combinação de ambos os processos os anteriores
\end{tabular}

Essa classificação tornar-se-á conhecida pelos teóricos e estudiosos da literatura pela designação de dramático, lírico e épico, respectivamente.

No gênero dramático, a figura do poeta quase desaparece e o texto se desenvolve por meio de diálogos que são apresentados em encenação teatral, tendo como referência a imitação das falas e/ou ações humanas. Essas serão consideradas ações boas (melhores do que as ações produzidas pelos homens); ações más (piores do que as produzidas pelos homens) e ações semelhantes às humanas. No gênero épico, a fala do poeta, que se expressa em seu próprio nome, alterna-se com os diálogos entre as personagens, constituindo-se em uma conjugação de duas outras técnicas (dramática e lírica). Em relação ao gênero lírico, esse se centra na fala do poeta que veicula suas próprias idéias e emoções. Esse gênero tende a absorver o ditirambo, a ode, o hino, a epigrama e a égloga - derivações líricas.

Convém lembrar que, em Aristóteles, as diferenciações formais do texto encontram-se intimamente ligadas ao conteúdo que os mesmos veiculam. Sobre esta questão, lembramos Horácio (65 a.C) que, dentre os seguidores de Aristóteles, associa a educação e o prazer à função moral e didática do texto literário. $\mathrm{O}$ crítico romano ressalta que o verdadeiro poeta é 
aquele que sabe adequar ao seu tema o ritmo, o tom e o metro certos, não podendo associar, por exemplo, ao tema da tragédia o metro próprio da comédia ou vice-versa. O hibridismo de formas é, nesta época, altamente condenável, o que deixará de ocorrer por volta do século XVIII-XIX, estendendo-se até nossos dias, passando a ser objeto de atenção, inquietação e estudos por parte de pesquisadores da área.

Ainda em relação aos conceitos formulados na antiguidade, três princípios acabam por fixar-se:

1.Cada gênero tem suas próprias regras de composição - Normatividade

2. Há gêneros considerados superiores, outros inferiores e outros ainda, equivalentes às ações humanas - Hierarquia

3. Não se admite, em princípio, combinar elementos de gêneros diferentes em um mesmo texto - Pureza

Considerando-se os desdobramentos advindos da antiguidade greco-latina sobre os gêneros literários, observamos que, a Idade Média não apresenta alterações substanciais sobre a questão. As modificações restringem-se, por vezes, à temática e, por outras, à estrutura formal do verso, cuja técnica das rimas era desconhecida na poesia antiga, ou ainda ao desenvolvimento da métrica, que se apóia nas sílabas e no acento de intensidade. Firma-se, neste período, a modalidade lírica, base da poesia trovadoresca difundida na Europa, em torno do século XIII. Lembramos ainda que, é na Idade Média que, Dante Alighieri distingue os gêneros, considerando-os nobres, médios e humildes. $\mathrm{O}$ primeiro tipo, tal como em Aristóteles, associa-se à tragédia e a epopéia; o segundo, à comédia (que se diferencia da tragédia pelo final feliz); e o terceiro, à elegia - canto em forma de poema lírico cujo tom é quase sempre terno e triste.

Com o Renascimento, a teoria dos gêneros retoma a Antigüidade e se firma como norma a ser seguida rigidamente. A mimesis volta a ser entendida estritamente como imitação da natureza, afastando-se da conotação criativa advinda do processo de transformação interpretado por Aristóteles. Assim sendo, a obra valorizada era aquela que mais se aproximava do real existente. $\mathrm{O}$ belo, associado aos ideais gregos, estabelecia modelos que deveriam ser incorporados como pressupostos básicos para qualquer forma de manifestação artística. Regras predeterminadas expressam também a continuidade da hierarquia das formas, assim, a tragédia e a epopéia continuam a ser considerados gêneros superiores que se contrapõem, por exemplo, à comédia - considerada como imitação das ações desprezíveis e, 
portanto, de caráter inferior na categoria dos gêneros. Desta forma, a imutabilidade das formas mantêm a classificação dos gêneros tal como já estavam presentes nos primeiros registros deixados pela Grécia antiga.

O despontar das manifestações pré-românticas, no século XVIII, coloca em pauta, novamente, a questão dos gêneros. Todavia, agora, a questão associa-se à mutabilidade das formas de manifestação artística.

O ímpeto do poeta romântico, que derrama suas emoções em textos, passa a constituir um novo conceito de criação, cuja expressividade abre espaço e valor às formas individualizadas e autônomas de literatura. A liberdade criativa abre espaço também à autonomia do poeta e, a teoria dos gêneros, tal como era concebida, passa a ser questionada. Em 1827, Victor Hugo é, dentre os poetas de sua época, o primeiro a manifestar-se pública e oficialmente em favor do hibridismo dos gêneros. Ironicamente, ele retoma a própria natureza em suas múltiplas manifestações para fundamentar a diversidade das formas e dos comportamentos e ideais humanos, concluindo que, qualquer processo de imitação do real deve trazer em seu bojo a pluralidade e diversidade existente no homem e no seu contexto natural, social e histórico.

Rompidas as estruturas rígidas de compreensão e classificação dos gêneros, o século XIX será o palco das grandes polêmicas sobre a questão, abrindo espaço para que diferentes pontos de vista se expressassem de forma a se opor ou apenas se complementar.

Nas últimas décadas desse século, o crítico francês, Ferdinand Brunetière (1849-1906) e o filósofo italiano, Benedetto Croce (1866-1952) vão contrapor-se conceitualmente, instaurando enfoques que se mantêm polêmicos até nossos dias.

Contextualizado com os avanços científicos e filosóficos do século XIX, Brunetière defende a idéia de evolução dos gêneros literários tal como se afirma, na época, a transformação e evolução das espécies naturais. Assim, as formas modernas de expressão literária seriam decorrências diretas das transformações ocorridas nas espécies. $\mathrm{O}$ vocábulo 'gênero', em sua acepção latina (genus-eris) que significa 'geração' - tempo de origem ou nascimento -, já indicaria a proximidade entre o fenômeno de transformação das espécies naturais e dos gêneros literários, na medida em que ambos cumpririam um ciclo vital de nascimento, desenvolvimento e morte. A morte ou extinção de um gênero daria origem a um novo gênero ou 'nova geração'. Assim compreendida a teoria dos gêneros literários, o ápice da tragédia clássica teria conduzido ao esgotamento de suas formas e sua conseqüente extinção. O drama romântico seria, portanto, uma decorrência da morte e/ou transformação dos traços da antiga tragédia clássica. 
Croce, por sua vez, vai opor-se radicalmente às idéias apresentadas pelo naturalista francês Brunetière, colocando a literatura numa dimensão criativa em que qualquer regra de submissão deveria ser repudiada. Criação artística, para o esteta italiano, não se atrelava à natureza exterior do homem ou aos fenômenos naturais, o que significa, necessariamente, uma desvinculação de modelos e conseqüente espaço de produção e manifestação pautados pela liberdade do artista. Os pressupostos básicos da arte poderiam chegar a admitir uma certa classificação dos gêneros, todavia, apenas e tão somente, como instrumento do crítico para a construção da história literária. Croce não admitia, em hipótese alguma, que a obra literária pudesse ser regida por categorias que fossem exteriores às suas qualidades composicionais. Pressupostos estranhos à obra não poderiam servir de parâmetro para qualificação valorativa do texto literário.

O pensamento de Croce não fica restrito à sua época, mas tem reverberações nas propostas modernas de estudo da literatura. A questão dos gêneros avança no final do século XIX e início do XX sem, contudo, atingir um patamar que fosse satisfatório ou consensual para as concepções da crítica contemporânea.

O século XX, pautado pelas novas contribuições dos Formalistas Russos, coloca-nos frente a questões que efetivamente nos fazem avançar na reflexão do fenômeno literário. Todavia, apesar da sistematização de novos procedimentos de abordagem da literatura, não podemos nos sentir satisfeitos, como estudiosos, com os instrumentais teóricos disponíveis, na medida em que o texto poético é uma realidade em permanente mutação.

Falar em gênero hoje, como classificação literária em compartimentos estanques, é objeto que suscita discussão. Mas, é preciso ter claro que esse é um enfoque do passado que tem sentido sim, para entender os textos clássicos ou alguns dos traços fundamentais da composição literária. Todavia, como recurso de análise, é certo também que esses instrumentais são por demais limitados ou segmentados, de forma a não darem conta do desafio que significa a pluralidade e complexidade do texto, sobretudo na literatura contemporânea.

As noções de 'sistema' e de 'dominante', formuladas por Tynianov (1976), representam, por exemplo, concepções dinâmicas e abrangentes que se colocam em consonância com as características mais atuais do texto literário, tal como aborda o trecho a seguir: “A unidade da obra não é uma entidade simétrica e fechada, mas uma integridade dinâmica que tem seu próprio desenvolvimento; seus elementos não são ligados por um sinal de igualdade e de adição, mas por sinais dinâmicos de correlação e integração" (TYNIANOV, 1976, p.102). 
Observar e/ou analisar o texto artístico exige estar relacionando ativamente séries literárias e não-literárias. Isto significa que a literatura é um sistema que se mantém em permanente diálogo interativo com sub-sistemas outros, sejam eles de caráter social, histórico e/ou cultural. Esses sub-sistemas podem ainda incorporar manifestações de cunho míticoreligioso ou até mesmo ideológico. A abertura e flexibilidade para a incorporação expressiva das mais diferentes manifestações de linguagem no seio da literatura revelam-na como um amplo sistema, todavia, nem por isso ela deixa de ter marcas próprias e diferenciadas.

Como característica particular do fenômeno literário, a noção de 'dominante', formulada por Roman Jakobson (1983), explicita uma das qualidades caracterizadoras daquilo que torna o texto especificamente literário. O conceito elaborado pelo formalista russo expressa o elemento que governa, determina e transforma o conjunto de caracteres do texto, garantindo-lhe coesão estrutural e especificidade estética. A dominante que rege o texto poético, segundo Jakobson, é a função poética da linguagem, a qual não apenas age de forma imperativa, mas acaba por criar uma hierarquia que determina subordinações conforme o caráter que se destaca no texto. Assim, considerando-se, por exemplo, uma narrativa épica, a função subordinada à poética seria a referencial, já que, na epopéia há sempre um referente factual, histórico e heróico a ser destacado. Da mesma forma, ao se falar no texto lírico, além do trabalho específico com a linguagem poética - trabalho esse que associa o valor semântico e formal do poema, construindo um adensamento de significados-, teríamos, em segunda instância, o trabalho em nível da função emotiva, cuja caracterização ocorre pela voz do poeta que, marcadamente presente no texto, expressa suas idéias e emoções.

Falar em gêneros literários no século XX, segundo os formalistas russos, é estar atento para um conjunto de procedimentos que tendem a agrupar textos, os quais, em princípio, se assemelham ou se diferenciam por suas qualidades poéticas estruturais. Atrelada à questão da poética propriamente dita, outros desafios vão se impor para a reflexão sobre os gêneros. $O$ problema do agrupamento normativo, baseado na fixação de normas rígidas, ou da liberdade criadora, que permite romper fronteiras e hibridizar formas diversas, ainda persiste.

Chegar a uma sistematização das formas poéticas que permita esclarecer e assegurar reflexão mais apurada é, portanto, questão atual, polêmica e desafiadora. Podemos dizer ainda que, nos últimos séculos, o problema tornou-se seguramente mais complexo. Se até o século XVIII, a tônica da literatura centrava-se na poesia, a partir de então, as formas narrativas passaram a se expandir e diversificar, colocando na arena uma nova multiplicidade de manifestações. Tais manifestações se movimentam das narrativas mais simples - a saga, o mito, o conto popular ou folclórico, etc - às mais complexas, como é o caso da novela e do 
romance, ou ainda, das narrativas menores que emergem em profusão, apontando para um novo desafio que é o de enfrentar e diferenciar os limites entre os diversos gêneros. Frente à complexidade de questões que o momento contemporâneo coloca, no que diz respeito à compreensão e possíveis diferenciações entre os gêneros, estaremos neste ensaio, centrando nossa atenção exatamente nos limites tênues entre a crônica e o conto.

A crônica, deslocando-se do contexto jornalístico (local de origem), insere-se cada vez mais no espaço literário e acaba por criar tal aproximação com o objeto de qualidade artística, que pode chegar, em seu grau máximo de literariedade, a ser considerada como um conto ficcional ou mesmo um texto em prosa poética. Este fato, cada vez mais presente na atualidade, acaba produzindo um fator tensional de difícil, senão quase impossível, diferenciação entre certos gêneros narrativos, anteriormente de fácil diferenciação.

\section{José Saramago: entre a crônica e o conto, o escritor e o crítico}

O Romantismo, tal como já abordado anteriormente, representou um marco no período da modernidade literária. Ele abriu espaço para a liberdade do escritor, o qual passou a se expressar sem compromisso com regras pré-estabelecidas. O movimento abriu espaço também para a manifestação de novas formas de expressão literária. A crônica e o conto estão entre as formas narrativas que, a partir dessa época, tomam corpo e expressividade, criando características específicas seja em relação à sua temática e estrutura composicional, seja em relação ao perfil de seu leitor. A proximidade entre estas duas manifestações narrativas não existiu, portanto, desde suas origens. Vejamos um pouco como nascem, expressam-se e se aproximam essas formas de organização de linguagem.

A crônica, originariamente, associa-se a um enfoque muito mais histórico do que literário. No início da era cristãa, ela designava um conjunto de fatos e/ou acontecimentos ordenados e expressos a partir de uma linha de sucessão cronológica. Esse enfoque não manifestava nenhuma intencionalidade interpretativa. Assim, a palavra grega chrónos que significa 'tempo' dá origem a chronikós e, posteriormente, chronica (latim). Esse significado original estende-se por toda renascença de forma que, até o século XVI, o sentido do termo designa aquilo que se conhece hoje como crônica histórica, ou seja, a visão do cronista como o relator da História, aquele que não se satisfaz em apenas apresentar, mas deve explicar sob sua ótica os acontecimentos que registra (cf. BENJAMIN, 1985).

A acepção moderna do termo começa a se manifestar no século XIX, quando passa a se libertar de sua conotação histórica e, via texto jornalístico, despe-se de seu antigo 
significado e passa por reformulações em seu discurso que a aproximam cada vez mais do texto de qualidade literária. Vejamos como se entende o hibridismo da crônica, como texto que, de origem histórica, desloca-se para o universo jornalístico e literário.

No início do século XIX, os jornais franceses inauguram um espaço curto (feuilletons), ao rodapé, geralmente da primeira página (au rez-de-chaussée), que passa a ser destinado à publicação de poemas, comentários sobre lançamento de livros, resenhas, narrativas curtas enfocando o cotidiano da cidade ou ainda, assuntos de interesse geral. Inicialmente, atribuiuse a este espaço certa conotação que se associava a assuntos pouco prestigiados. É certo que esse espaço era marcado por uma saudável liberdade de escrita, fato importante para um tipo de publicação diária que logo viria a se popularizar, ganhando adeptos nas mais diferentes camadas sociais. Os folhetins, tal como a popularização do jornal, são decorrências da revolução burguesa - movimento responsável pelo surgimento de veículos de comunicação mais acessíveis aos interesses gerais, assim como às camadas menos intelectualizadas da população. O espaço dos folhetins, em princípio mais descompromissado, estava em sintonia quase direta com as transformações e modernização dos grandes centros urbanos, que não apenas produziam mais notícias, mas necessitavam também de canais para sua divulgação. Assim, eles passam a designar um espaço de registro dos fatos cotidianos, na verdade, quase um registro histórico do olhar aguçado do cronista que flagra a cidade e passa a revelar ao seu leitor, os fatos e interpretações sensíveis, quase poéticas, do seu espaço de vida moderna.

Pode-se afirmar que, é sob essa perspectiva que o gênero crônica inicia a aliança entre os gêneros jornalístico e literário. A redução de um discurso de caráter opinativo associado à construção de outros tipos de discurso - que se abrem para diferentes pontos de vista, assim como para a elaboração de níveis de afastamento do real adensados por estruturas poéticas criam um novo tecido textual que torna ambíguas tanto as estruturas composicionais da crônica quanto da prosa ficcional.

A visão do escritor, claramente expressa na crônica, começa a perder sua nitidez e, em diferentes níveis de gradação, vai se tornando obliterada e acaba por abrir espaços para que a função estética se expresse e mesmo se sobreponha à função referencial da linguagem. A transitoriedade, como característica peculiar da crônica, alocada na página do jornal, perde sentido - à medida que essa se desloca da imprensa efêmera - e conquista o espaço nobre do livro de ficção. O distanciamento da crônica e a aproximação do conto manifestam-se exatamente pelo transitar entre o discurso referencial propriamente dito e a construção poética da linguagem. 
A transmutação da crônica para o conto pode trazer consigo tanto a expressão lírica da palavra quanto a ironia ou dramaticidade da narrativa, de maneira que, entre uma e outra, qualquer forma plástica do discurso pode se fazer presente, retomando gêneros cujas modalidades são marcantes desde a Antigüidade. É o que se pode observar no conjunto de crônicas A bagagem do viajante, de José Saramago (1996). Múltiplas sugestões advêm da leitura das referidas crônicas. Desentranhar da crônica, a prosa poética é um exercício que propomos como estudo, por exemplo, de "No pátio, um jardim de rosas" (SARAMAGO, 1996, p.79-81).

Resguardando elementos básicos da crônica, tais como, a função emotiva e referencial da linguagem - que expressam pensamentos e emoções sensíveis do cronista como homem que vive, sente e observa atentamente os fatos e espaços que o circundam -, o texto se desenvolve assumindo características peculiares da prosa poética. Ele está centrado em um conteúdo lírico e recria o real por meio do adensamento da linguagem, da desautomatização da percepção e da singularização dos fatos narrados. Esses últimos - os fatos narrados - são retirados do real e assumem caráter textual inovador, metafórico e, acima de tudo, poético. Entretanto, considerando-se que o grau de referencialidade dessa crônica ainda é maior que seu grau de literariedade, explicitamos algumas passagens para que se possa observar não só como se inicia a transmutação do gênero, mas ainda como o discurso se transforma pela contaminação poética:

Ao cair da tarde [...], depois do dia de trabalho, [...] gosto de andar pelas ruas da cidade, distraído para os que me conhecem, agudamente atento para todo o desconhecido, como se procurasse decididamente outro mundo. Posso então parar [...] radiografar rostos para além dos próprios ossos, penetrar na cidade como se mergulhasse num fluido [...] Nestas ocasiões é que faço minhas grandes descobertas [...] para a captação mais viva do que me cerca. (SARAMAGO, 1996, p. 79)

A linguagem das primeiras linhas do trecho citado parece não deixar dúvida de que possui uma referencialidade explícita: "cair da tarde"/ "um dia de trabalho"/ "andar pelas ruas da cidade" / etc. Todavia, uma observação atenta revela uma oposição interessante entre "distraído para os que me conhecem, agudamente atento para todo o desconhecido". As palavras 'distraído' e 'atento' além de apresentarem carga semântica de oposição, associam-se a outra oposição textual - conhecer e desconhecer - que adensa e amplia seus significados, isto porque, para aquele que conduz a narrativa, o interesse reside, exatamente, no desconhecido: é nele que toda a atenção se concentra. O poeta é aquele para quem o elemento propulsor da criação se encontra sempre no desconhecido, ou seja, na palavra reveladora, aquela que o conduzirá a descobrir o que está encoberto seja pela postura ingênua do ato de ler, seja pela limitação do olhar. 
Ainda nesse trecho, logo ao início da narrativa, é possível perceber um trabalho metalinguístico com a crônica ao mesmo tempo em que se (con)funde a figura do cronista com a do poeta. O primeiro registra no discurso sua posição de observador dos fatos; sua palavra veicula seu próprio olhar. O segundo cria, na linguagem, um registro denso de tudo o que o rodeia. A tradução ou criação dos fatos sobre a cidade e as pessoas que o cercam é marcada pela sensibilidade, que tateia e percebe com os sentidos, mais do que pela própria razão. É o olhar poético que busca a descoberta do que está encoberto; é o olhar anônimo a procura do desconhecido. Poderíamos arriscar dizer, que é o novo fazendo-se no e do velho. É o texto sobrepondo-se aos fatos: o que era real transforma-se em textual. A notícia vira crônica que vira poesia - esvaziamento de formas para construção de novas formas.

"Radiografar rostos para além dos próprios ossos" é metáfora que desafia possíveis significados e exige do leitor a construção imagética da essência do ser - o que existe para além dos próprios ossos? Preencher espaços de significação e diversificar horizontes de leitura já é inscrição do universo poético. O escritor, ensinando a ler a crônica, assume também uma lição de poesia - escritor e crítico se completam.

A palavra como imagem esvazia, portanto, o caráter informativo da crônica e passa a preenchê-la de conotações líricas, tal como expressa também o trecho seguinte:

Foi num dia assim [...] que descobri [...] a ruína [...] um prédio de dois andares [...] uma fronteira esfolada, toda fendida, com placas de esclerose [...] causadas pela queda da argamassa [...]. Na empena do prédio ao lado, à altura dos olhos, uma frase escrita em letras vermelhas, maiúsculas, planta de repente um jardim de rosas: A LENA AMA O RUI. (SARAMAGO, 1996, p.80).

A descrição do prédio, tal como é apresentada ao leitor, deixa transparecer para além de fatos possivelmente observados, a projeção do imaginário que "planta de repente um jardim de rosas". São rosas/palavras que se revelam aos olhos do cronista e desabrocham como flores aos olhos do poeta apaixonado pelas palavras vermelhas. A construção gráficovisual estabelece a equivalência entre flores e palavras; rosas no jardim e letras vermelhas nascidas na empena do prédio, o que significa, uma sugestão de equivalências responsável pela qualidade ambígua e polivalente do texto, ou ainda, pelo transitar por entre o discurso referencial e poético.

A afirmação de amor inscrita no muro de um prédio abandonado, ao ser flagrada pelo olhar do cronista, transforma-se em inquietação poética. O texto faz conviver em seu discurso a voz do cronista, do jornalista, do contista, do poeta, ou simplesmente, do narrador. A crônica se faz metalinguagem e faz pensar sobre si mesma. Afinal, faz sentido pretender classificar os gêneros no texto? 
Ao tomarmos como referência, por exemplo, "A oficina do escultor", outro texto que compõe o conjunto das crônicas de A bagagem do viajante, esse processo de transmutação entre gêneros se perde totalmente e não se consegue mais detectar referências sejam elas temáticas ou estruturais, em relação à crônica. Nesse texto, como dominante inquestionável, imperam as marcas poéticas da narrativa. Já não se faz mais possível apreender o fato extratextual. Se existe um fato narrativo, este é o próprio texto como conjunto de sugestões sinestésicas que se interpenetram. Ele sugere sons, imagens e sensações diversas, responsáveis pela configuração da escultura/escritura que se produz no interior da oficina lugar de trabalho, onde ocorrem grandes transformações.

O escultor/escritor não recorre a fatos observados em um universo exterior. Sua matéria prima é a palavra. Com ela, ele se movimenta pelas "telas brancas", e no universo do possível, faz "a música abrir-se como flor rubra gigantesca". A luta corpo a corpo com a palavra resulta em momentos poéticos de total esvaziamento sígnico. Esses últimos - os signos - desvinculados de seus significados convencionais vagam pela tela branca da página à espera de que o leitor os enfrente como desafio e busque significados outros para preenchêlos, criando novas sintaxes que expressem formas inovadores de olhar e interpretar. $\mathrm{O}$ que significa uma oficina de escultor, senão um espaço de permanente e inesperadas criações?

A oficina do escultor é alta como uma caverna que esvaziasse uma montanha, sonora como um poço, e os sons caem dentro dela de um modo redondo, líqüido, e são como água fria salpicando um sino de cristal.... (SARAMAGO, 1996, p. 175)

A oficina construída no texto despe-se de qualquer referencialidade que pudesse ser alvo de atenção de um cronista. Não é possível reconstituir um espaço de trabalho (uma oficina) com objetos lingüísticos meramente sensórios. Penetramos no universo poético, o automatismo de nossa percepção não encontra referenciais para o processo de decodificação. O leitor vê-se obrigado a buscar equivalências, construir significados que o motivem a uma nova visão de espaço - não necessariamente um lugar físico, geográfico, mas um espaço de criação imaginário, onde tudo é possível. Sons, cores, movimentos, odores, enfim, motivações não convencionais asseguram, nesse texto, a percepção estética do objeto.

A oficina do escultor/escritor foi retirada de seu contexto habitual, revelando - a nós leitores - uma faceta insólita do espaço. O artista da palavra destruiu clichês, associações esteriotipadas (por exemplo, caverna enquanto espaço vazio) e impôs uma complexa percepção sensorial, que propõe o vazio (?!) como espaço de onde tudo existe em potencial “como uma caverna que esvaziasse uma montanha" (SARAMAGO, 1996, p.175) -, ou seja, espaço pleno que traz em suas entranhas a densidade de 'todas as possibilidades'. 
A caverna, ao longo do texto, reitera-se por meio de representações expressas, por exemplo, nos vocábulos vulcão/ poço/ útero e texto. O discurso constrói em seu próprio interior o fato literário. Relembrando Tynianov,

A existência de um fato como fato literário depende de sua qualidade diferencial, [...] em outros termos de sua função [...]. A função autônoma, isto é a correlação de um elemento com uma série de elementos semelhantes que pertencem a outras séries, é uma condição necessária à função construtiva deste elemento. (TYNIANOV, 1976, p.143)

É assim que "a oficina transforma-se em sala de concerto, em catedral, em vulcão ..." (SARAMAGO, 1996, p.175). As equivalências evidenciam enfaticamente a dominante poética do texto, cujos referenciais só podem ser encontrados no próprio texto como uma multiplicidade de espelhos, que criam ecos imagéticos, sonoros, sensoriais.

Saramago, como artista da palavra, compõe e decompõe significados, cria signos tal como o escultor cria formas sensíveis e plurais que se movimentam e se transformam em sintonia contínua com o próprio homem, cuja mente microcósmica pensa o mundo e a si mesma em paradigmas desafiadores. Eis a presença do escritor, do poeta, do crítico da contemporaneidade. Seria possível negar-lhe ou mesmo questionar sobre estes seus atributos?

\section{Referências}

ARISTÓTELES. Arte Poética. In: Arte Retórica e Arte Poética. Rio de Janeiro: Ediouro, s/d.

BENJAMIN, Walter. O narrador. In: Magia e técnica, arte e política. São Paulo: Brasiliense, 1985.

CÂNDIDO, Antonio. A vida ao rés-do-chão. In: CÂNDIDO, Antonio et al. A crônica: o gênero, sua fixação e suas transformações no Brasil. São Paulo, Campinas: UNICAMP, 1992.

COUTINHO, Afrânio. Ensaio e Crítica. In: A literatura no Brasil. Rio de Janeiro: Sul Americana, 1971.

JAKOBSON, Roman. O dominante. In: LIMA, Luiz Costa. Teoria da literatura em suas fontes. Rio de Janeiro: Francisco Alves, 1983.

LIMA, Luiz Costa. A questão dos gêneros. In: de Janeiro: Francisco Alves, 1983. vol. 1. . Teoria da literatura em suas fontes. Rio

PLATÃO. A República. São Paulo: Martin Claret, 2002.

SARAMAGO, José. A bagagem do viajante. São Paulo: Companhia das Letras, 1996.

TYNIANOV, J. A noção de construção. In: EIKHENBAUM; et al. Teoria da Literatura formalistas russos. Organização de Dionísio de Oliveira Toledo. Porto Alegre: Globo, 1976. 